Research Article

Open Access

\title{
Study of Visual Mental Imagery on the Aspects of Background, Foreground, Organization and Vividness of the Stimulus
}

\author{
Himani Raichur ${ }^{1 \star}$ and Revati Vijay Shivnekar ${ }^{2}$ \\ ${ }^{1}$ Assistant Professor, Department of Psychology, Fergusson College, Pune, India \\ ${ }^{2}$ Student, Department of Psychology, Fergusson College, Pune, India
}

\section{Article Info}

*Corresponding author:

Himani Raichur

Assistant Professor

Department of Psychology

Fergusson College

Pune, India

E-mail: himaniprasad27@gmail.com

Received: October 18, 2017
Accepted: November 07, 2017
Published: November 13, 2017

Citation: Raichur H, Shivnekar RV. Study of Visual Mental Imagery on the Aspects of Background, Foreground, Organization and Vividness of the Stimulus. Madridge $J$ Neurosci. 2017; 1(1): 32-37.

doi: $10.18689 /$ mjns-1000106

Copyright: (c) 2017 The Author(s). This work is licensed under a Creative Commons Attribution 4.0 International License, which permits unrestricted use, distribution, and reproduction in any medium, provided the original work is properly cited.

Published by Madridge Publishers

\begin{abstract}
This study inspected visual mental imagery on four aspects-two of which were location based: Background (peripherally located), foreground (centrally located); and the other two were related to qualities of the images: Organization (Structure), and vividness (colours). A sample of 43 young adult females between the ages of 18 and 22 was taken. The sample was shown a picture of a building for 10 seconds before taking it away. After the subjects formed a visual image, they were asked to pick the prime from other 3 distracters. This process was repeated for all 12 sets. The scoring was done by counting errors on each of the four aspects. It was hypothesized that errors in the sets with background (peripheral) changes will be more than foreground (central) changes; while errors in the sets with organization (structure) will be more than vividness (colour) changes. The study found no significant difference in the number of errors between background (peripheral) and foreground (central) changes. However, errors committed in organization (structure) and vividness (colour) changes differed significantly, with more errors in organization (structure). Further enquiry into the eye movements involved in image inspection and visual mental imagery is suggested.
\end{abstract}

Keywords: Visual mental imagery; Background (peripheral location) and foreground (central Location) of visual images; Organization (structure) and vividness (colour) of visual images.

\section{Introduction}

The purpose of the present study was to investigate visual mental imagery in young adult females between the ages of 18 to 22 . The aspects under the study were foreground, background, vividness, and organization of the said imagery. Background was taken to mean the peripheral area while foreground as the central area of the prime stimulus. Vividness was examined in terms of colours while the organization in terms of particular structures. The task involved generation of visual imagery of the prime stimulus in its absence and then selecting an appropriate stimulus resembling the prime while discarding the three distracters.

Although visual perception and visual imagery differ in their nature and realization, Stephen Kosslyn's Image Scanning Task showed that inspection of visual imagery possesses some qualities of visual perception. One of the important findings in this study was that examining objects which are farther away in the imagery takes longer time than the objects which are closer [1]. The current study attempts to extend this finding to make a distinction between errors committed in recognizing the appropriate stimulus from the background or the foreground of the prime. 
It has been postulated through various studies that colours and shape recognition of an object occurs as two separate processes [2]. This position has also been supported by neuroscientific research, in which it has been noted that colour, structure, movement, and the depth of an object is processed separately and then united to give an individual a full perceptive experience [3]. Some studies have shown preattentive, more ready processing of colours as compared to the form [4], while other studies do not note any such difference [5]. Owing to the disparity in these results, the present study tries to investigate vividness in terms of colours and organization in structures by measuring the number of errors made while selecting the appropriate cue.

The findings of this research may provide an impetus to further the current knowledge of the nature of visual mental imagery.

\section{Basic Concepts}

\section{Mental Imagery}

Mental imagery is defined as a quasi perceptual experience across all sensory modalities $[6,7,8]$. It differs from sensory perception mainly on the existence of the external cues in the immediate environment. It resembles the perceptual experience, but occurs in the absence of any appropriate external stimuli [6]. Further, imagery is found to occur only under certain circumstances like, when there is a comparison of concepts [12], when the concepts are defined in a great detail or when the concepts are not very familiar. Unlike perception, the individual differences found in mental imagery are more peculiar [9]. Researchers have found that based on the vividness or realness of imagery, people can be categorised into high or low imagers. Mental imagery exists in relation of all sensory modes viz., visual, auditory, gustatory, tactile and olfactory as well as visceral sensations and emotional feeling [10].

\section{Visual Mental Imagery}

Visual mental imagery addresses the visual modality of the imagery. It is, traditionally, the most discussed variety of mental imagery [6]. The attempts at understanding this phenomenon have resulted into proposition of two dominant theories which appear to be contrasting. Following is a short description of these two views:

\section{Analogue Code}

The analogue code is a representation that closely resembles the inducing stimuli, object, concept et cetera. Precisely, this theory holds true thatmental representations are like pictures with spatial representational properties as if put on a Cartesian coordinate system. As a leading supporter of this theory, Kosslyn describes visual mental imagery as digitized pictures that a brain can understand $[11,12]$. Increasing evidence from the neuroscience suggests that neural substrates of visual imagery are similar to those of visual perception further corroborating this model $[13,14]$.

\section{Propositional Code}

Proponents of this theory argue that imagery is in fact stored in an abstract representation which is neither visual nor spatial and does not resemble the inducing stimulus in any way [15]. While denying the experience of analogical representation of objects or concepts, Pylyshyn further emphasized on the underlying format of information processing. According to this theory, the processing of information stored in the imagery happens not in the form of picture-like entities, but in propositional codes which resemble an inner language, for which no specific perceptual mechanism needs to be activated [6].

The analogue-propositional debate or commonly known as the 'imagery debate' has not yet been fully resolved, as the research in neuroscience suggests support for both of them. In the current study, the participants were encouraged to use the analogue code but the use of propositional code cannot be ruled out.

\section{Background of the Prime}

Operational definition: In the study, the background of the prime was taken as the peripherally situated structures and colours.

\section{Foreground of the Prime}

Operational definition: In the study, the foreground of the prime stimulus was taken as the centrally located structures and colours.

\section{Organization of Visual Mental Imagery}

Some researchers have argued in the past that visual imagery is spatial and not visual. But Farah notes that visual imagery, in fact, has two distinct components in representation, visual and spatial. The later view has also been supported by her research on brain-damaged patients [13].

Operational definition: In the present study, under the title of organization of visual imagery, the spatial representation is taken under consideration. That is, organization is taken to mean the positions of the structures of the prime stimulus as seen in the prime cue. It was measured by the number of errors committed while selecting the prime stimulus from the distracter stimuli which differed only in the positions of the structures.

\section{Vividness of Visual Mental Imagery}

From the literature review there seems to be an issue with defining the vividness of visual mental imagery. David F. Marks, a leading figure in the conceptualization of the phenomenon, defined vividness of mental imagery in terms of clarity and liveliness, as well as similarity to the actual or inducing percept [16]. Recognizing this as an aspect of visual mental imagery, vividness has also been elaborated in terms of realness of the imagery [17]. In spite of this, vividness is well researched. It has found to have correlations with arousal, 
valence and emotionality [10]. In an attempt to quantify it, Marks developed a test, Vividness of Visual Imagery Questionnaire (VIQ), and although it has had its critics in Ahsen and Hilgard, it is taken to possess content validity, criterion validity and reliability [16]. McKelvie further notes that though there are issues with defining the phenomenon, Marks' VVIQ demonstrates promising correlation with eidetic imagery, dream frequency and hypnotic susceptibility [17].

Operational definition: In the present study, the vividness aspect was studied in terms of colours from the prime stimuli. It was measured by the number of errors committed while selecting the prime stimulus from the distracter stimuli which differed only in colours.

\section{Literature Review}

Philosophers' quest in investigating the 'mind's eye' involved putting forth theories that were, in those times, were not empirically examined. Many centuries later, when psychology delineated its limits by employing scientific enquiry to find answers philosophers had been asking, early leaders of the field, notably Wundt, Titchener and William James, examined this phenomenon in their capacities-Wundt used introspection, Titchener added emphasis on semantics behind imagery and James asserted that every thought process is essentially a verbal or visual type of imagery [6]. Even with this initial enthusiasm, under B. F. Skinner's 'radical behaviourism' studying a phenomenon like imagery, which was inherently implicit, took a back seat $[18,19]$. After the cognitive revolution which took place in 1960s, traditionally the focus was on theorising the nature of mental imagery. Shepard and Metzler in 1972, attempted to objectively examine mental imagery through the Mental Rotation task which proved to be an impetus for furthering a quantifiable and objective research enquiry of mental imagery [20, 21, 22]. Upon reviewing the literature, the research interests seem to have shifted to more pragmatic investigations like applications of imagery in creativity [23, 24], mental health [18] et cetera. But there are questions about visual imagery and its nature that still remain unanswered.

One of the main objectives of this research, hence, was to examine the imagery as it occurs in our experience. The current study draws upon research methods used by Nori and Giusbetti in 2006 in their research to study nature of inspection of visual mental imagery by using the Building Task $[25,26]$. In the original experiment, the subjects were shown a picture of a building for 3 seconds and then the original or the prime picture was reintroduced with three distracters, out of which, the subjects were required to choose the prime cue. Though this research employed an ingenious scheme to study inspection of visual images, it involved structural, chromatic and orientation changes all together. In result, the study ignores potential differences in duplication of above mentioned aspects of the visual images. As Chmiel's study in 1989 had shown that processing of colours and form may occur through different attentive processes, this research failed to take these distinctions under consideration [4].
In this project, the prime stimulus was shown for 10 seconds as opposed to 3 seconds in the original study to give participants enough time to consider it while keeping the period short enough that the image stays in the working memory. Moreover, the subjects were young adult females from the age group 18 to 22 from Fergusson College. As mental imagery has been found to be a function of age and gender $[27,28]$, these variables were controlled.

\section{Rationale and Significance of the Study}

Even though the current focus of the field has been shifted to a more applied research space, there is much more left to be answered about the nature of the visual mental imagery. Upon the review of literature, it can be observed that visual images have not been thoroughly explored in terms of duplication of vividness (in terms of colours) and organization (in terms of positions of structures) in the visual images. The present study, hence, tries to elaborate more on these aspects to extend our knowledge of nature of visual mental imagery. Furthermore, duplication of foreground and background from the prime stimulus is also addressed in this study. Hence, this experiment is a concise study of vividness, organization, foreground and background of the visual mental imagery.

This experiment takes a note of the serious need for establishing objective evidence on the nature of visual images. It aims to aid comprehension of to what extent visual imagery resembles the actual perceptual experience and whether the duplication of the prime stimulus is better in some aspects than others.

\section{Hypotheses}

The following hypotheses were formulated in the current study:

1. The errors committed in sets with background changes will be more than in sets with foreground changes.

2. The errors committed in sets with changes in organization will be more than in sets with changes in vividness.

\section{Method}

\section{Experimental Design}

The task was a modified edition of the Building Task, devised by Nori and Giusbetti in 2006 for examining inspection of visual mental imagery.

In this experiment, the subject was shown a coloured, horizontally oriented picture of a building on an A4 size paper for 10 seconds. This picture was referred to as the 'prime stimuli'. The subject was told to pay particular attention to colours, positions of different structures and was discouraged from counting windows, doors or other structures. After 10 seconds the picture was taken away and the subject was given 5 seconds to recreate the prime stimulus in her head. The subject was allowed to take more time if needed. After the 
subject indicated that she is ready, the experimenter showed 4 pictures which, unwitting to the subject, had 1 picture exactly resembling the prime stimulus and its 3 variations, referred to as the 'distracters'. Out of the four pictures presented, the subject's task was to recognize the prime stimulus correctly. The last step had no time limit. This procedure was repeated for all 12 sets. Before starting the experiment, the subject was given one trial and if she wished, another trial was given.

The experiment had 12 sets in total. Out of the 12 sets, 6 had changes in the background while rest of the 6 sets had the foreground changes. Further, 6 had organizational changes (in positions of structures) while 6 had changes in the vividness (in colours). Following table explains this distribution:

Table 1. Experimental design of the research

\begin{tabular}{|c|c|c|c|}
\hline & $\begin{array}{c}\text { Background } \\
\text { changes }\end{array}$ & $\begin{array}{c}\text { Foreground } \\
\text { changes }\end{array}$ & Total \\
\hline Organizational changes & 3 & 3 & 6 \\
\hline Vividness changes & 3 & 3 & 6 \\
\hline Total no. of sets & 6 & 6 & 12 \\
\hline
\end{tabular}

The scoring was done by giving 1 point for error in each set and 0 for a correct answer. In this way, scores for sets with background, foreground, organizational and vividness changes were obtained separately.

\section{Participants}

This experiment was conducted on young adult females from the age group 18 to 22 (mean age $\approx 20.2$ years) in a sample of 43 females $(n=43)$. To control the relevant variables of gender and intelligence, all the participants were female students studying at Fergusson College, Pune, India in an undergraduate course and had obtained a first class $(60 \%)$ or above in their $12^{\text {th }}$ grade examination. The sample was collected through the snowball sampling method.

\section{Results}

To test the hypotheses, all four aspects of visual mental imagery under the study were tested for normal distribution. All these aspects - namely, background, foreground, vividness and organization - measured in terms of errors committed were found to be normally distributed.

To find out whether the means of four conditions were significantly different, one way ANOVA was done. The analysis showed that the difference among these four means was significant at .001 confidence level. (Refer to table 3).

To analyse further, mean scores of errors committed on each aspect under the study were compared by using Sheffe's Posthoc test. It was found that, there exists no significant difference in means between errors committed in background changes and errors committed with foreground changes (Table 4). However, the results showed that there exists a significant difference in means between errors committed in organization changes and errors committed in vividness changes (Table 4).
Table 2. Showing means, median and standard deviation of four experimental groups

\begin{tabular}{|l|c|c|c|c|}
\hline \multicolumn{1}{|c|}{ Group } & Background & Foreground & Organization & Vividness \\
\hline Mean & 3.12 & 3.02 & 3.53 & 2.53 \\
\hline Median & 3.00 & 3.00 & 3.00 & 3.00 \\
\hline Standard Deviation & 1.21 & 1.03 & 1.20 & 1.07 \\
\hline
\end{tabular}

Table 3. Analysis of Variance (ANOVA) for Visual Mental Imagery among four experimental groups.

\begin{tabular}{|l|r|r|r|r|r|}
\hline & $\begin{array}{r}\text { Sum of } \\
\text { Squares }\end{array}$ & \multicolumn{1}{c|}{ df } & Mean Square & F & \multicolumn{1}{c|}{ Sig. } \\
\hline Between Groups & 21.738 & 3 & 7.246 & 5.615 & .001 \\
\hline Within Groups & 216.791 & 168 & 1.290 & & \\
\hline Total & 238.529 & 171 & & & \\
\hline
\end{tabular}

Table 4. Comparison of Visual Mental Imagery among four experimental groups by Sheffe's Posthoc test

Dependent Variable: Errors

\begin{tabular}{|c|c|c|c|c|c|c|}
\hline \multirow{2}{*}{$\begin{array}{l}\text { (I) } \\
\text { Conditions }\end{array}$} & \multirow{2}{*}{$\begin{array}{l}(J) \\
\text { Conditions }\end{array}$} & \multirow{2}{*}{$\begin{array}{c}\text { Mean } \\
\text { Difference } \\
(I-J)\end{array}$} & \multirow{2}{*}{$\begin{array}{l}\text { Std. } \\
\text { Error }\end{array}$} & \multirow{2}{*}{ Sig. } & \multicolumn{2}{|c|}{$\begin{array}{c}\text { 95\% Confidence } \\
\text { Interval }\end{array}$} \\
\hline & & & & & $\begin{array}{l}\text { Lower } \\
\text { Bound }\end{array}$ & $\begin{array}{l}\text { Upper } \\
\text { Bound }\end{array}$ \\
\hline \multirow{3}{*}{1} & 2 & .093 & .245 & .986 & -.60 & .78 \\
\hline & 3 & -.419 & .245 & .407 & -1.11 & .27 \\
\hline & 4 & .581 & .245 & .135 & -.11 & 1.27 \\
\hline \multirow{3}{*}{2} & 1 & -.093 & .245 & .986 & -.78 & .60 \\
\hline & 3 & -.512 & .245 & .229 & -1.20 & .18 \\
\hline & 4 & .488 & .245 & .268 & -.20 & 1.18 \\
\hline \multirow{3}{*}{3} & 1 & .419 & .245 & .407 & -.27 & 1.11 \\
\hline & 2 & .512 & .245 & .229 & -.18 & 1.20 \\
\hline & 4 & $1.000^{*}$ & .245 & .001 & .31 & 1.69 \\
\hline \multirow{3}{*}{4} & 1 & -.581 & .245 & .135 & -1.27 & .11 \\
\hline & 2 & -.488 & .245 & .268 & -1.18 & .20 \\
\hline & 3 & $-1.000^{*}$ & .245 & .001 & -1.69 & -.31 \\
\hline
\end{tabular}

*. The mean difference is significant at the 0.05 level.

\section{Discussion}

When the four aspects of visual mental imagery were compared, as seen in Table 3, the $\mathrm{F}$ ratio was significant; indicating that the difference between the four groups was significant. Therefore further analysis was done using Sheffe's Posthoc test (Table 4). As seen in table 4, the first hypothesis which stated that, 'the errors committed in sets with background (peripheral) changes will be more than in sets with foreground (central) changes' was not supported. The difference between means of condition 1 (background / peripheral) and 2 (foreground / central), as seen in table 4, is not significant. From Table 2, the mean of errors in background was 3.12 and standard deviation was 1.21 while the mean of errors in foreground was 3.02 and standard deviation was 1.03. One possible reason could be that, as pointed out by Jeannerod, movement or perceived movement in visual imagery is more readily recalled than aspects of the visual images [29]. The experiment did not count for eye movement fixations. Moreover, it is found that the eye movements while inspecting visual images play significant role in construction of mental images. Hence, it could not be denied that the subjects' recall was affected by the tendency to focus more on some parts of the images which had nothing to do with their positioning (background and foreground, in this case) but 
was rather influenced by other aspects of the images. These different aspects of the images (apparent or perceived subjectively by participants) and which were not taken under consideration as possible dependent variables could be the reason why the significant difference between errors in background (peripheral) and foreground (central) conditions was not observed.

The second hypothesis stating that 'the errors committed in sets with changes in organization (structure) will be more than in sets with changes in vividness (colour)' was proved after the statistical analysis (Refer to table 4). The mean of errors in the sets with organization was 3.53 and standard deviation was 1.20 . The mean of errors in the sets with vividness, on the other hand, was 2.53 and standard deviation was 1.07 (Refer to Table 2). A comparison of the two means proved that there exists a difference between the two at $5 \%$ significance level, as seen in table 4 . This showed that recall or retention of colours is more accurate than positions of structures. Further, these results exemplified a possible difference in processing of these two aspects of visual mental imagery. The hypothesis took under consideration that visual perception involves separate information processing of different aspects of the visual field. Though how these aspects are bound together to give a 'wholesome' picture is not clear, the research in visual neuroscience has established that colour input from the visual field takes the ventral pathway to the temporal region while the organization of the visual field is fed to the parietal lobe by the dorsal pathway. As it has been mentioned before, visual imagery and visual perception overlap in many aspects of their respective manifestation. Hence, separate processing systems were hypothesized to belie the organization and colour processing of imagery. The significant difference found between vividness and organization of imagery in the present study supports the idea of separate processing of these aspects as is found in the visual system.

\section{Conclusion}

The current study concluded that in case of young adult females of 18 to 22 years of age, there was no significant difference in errors committed in background (peripheral) and foreground (central) changes. However, significant differences were found in errors committed in organization (structure) and vividness (colour) changes, with more errors in organization / structure.

\section{Limitations and Suggestions}

One of the factors that the present study did not undertake was that subjective differences in generation and inspection of visual mental imagery. It has been found in Paivio's study that people can be differentiated as high- or low-imager based on clarity of the images $[30,31]$. If the subjects were pre-tested, segregated in to groups depending on such clarity and then tested, then the data would have been more infallible.

Further, some subjects reported subjective relevance with some prime stimuli presented. This could potentially mean that the inspection of such visual images was easier to inspect than others. As the images used as prime were only buildings, there is more chance of personal relevance affecting judgments of the subjects. Extending this point to the observation made in the discussion section, the experiment did not control the inherent properties of the images which could have affected their recall. For example, a participant, in the subjective report after the study, noted that she could guess the correct picture not by the colours or organization but rather by the absence of a flock of birds. Similarly presence or absence of particular cues from the images could have made them more or less recallable.

The experiment did not control the spatial area of the images which got manipulated in the distracters. It could be possible that in some sets the area which underwent changes was bigger and hence, more apparent than other sets.

\section{Conflict of interest}

The authors confirm that there is no conflict of interest regarding this manuscript.

\section{Acknowledgement}

We thank all the faculty members of the Department of Psychology at Fergusson College for providing us with the resources and their valuable insight which aided this research along the way. We are especially grateful to Dr. Sheetal Ruikar for helping us in the design of the research. Special thanks to the participants without whom it would not have been possible to complete the project.

\section{References}

1. Kosslyn SM. Scanning visual images: Some structural implications. Attention, Perception, \& Psychophysics. 1973; 14(1): 90-94.

2. Cant JS, Large M, McCall L, Goodale MA. Independent Processing of Form, Colour, and Texture in Object Perception. Perception. 2008; 37(1): 57-78. doi: 10.1068/p5727

3. Livingstone MS, Hubel DH. Psychophysical separate channels for the perception of form, color, movement, and depth. Journal of Neuroscience. 1987; 7(11): 3416-3468.

4. Chmiel N. Response effects in the perception of conjunctions of colour and form. Psychological Research. 1989; 51(3): 117-122.

5. Walker $P$, Cuthbert L. Remembering visual feature conjunctions: Visual memory for shape-colour associations is object-based. Visual Cognition. 1998; 5(4): 409-455. doi: 10.1080/713756794

6. Thomas N. Mental Imagery. 2017

7. Pearson DG, Deeprose C, Wallace-Hadrill SM, Heyes SB, Holmes EA. Assessing mental imagery in clinical psychology: A review of imagery measures and a guiding framework. Clinical Psychology Review. 2013; 33(1): 1-23. doi: 10.1016/j.cpr.2012.09.001

8. Roth JD, Kosslyn SM. Construction of the third dimension in mental imagery. Cognitive Psychology. 1988; 20(3): 344-361. doi: 10.1016/00100285(88)90003-5

9. Reisberg D, Culver LC, Heuer F, Fischman D. Visual memory: When imagery vividness makes a difference. Journal of Mental Imagery. 1986

10. Andrade J, May J, Deeprose C, Baugh SJ, Ganis G. Assessing vividness of mental imagery: the Plymouth sensory imagery questionnaire. British Journal of Psychology. 2014; 105(4), 547-563. doi: 10.1111/bjop.12050 
11. Kosslyn SM, Shwartz SP. A simulation of visual imagery. Cognitive Science. 1977; 1(3): 265-295. doi: 10.1016/S0364-0213(77)80020-7

12. Kosslyn SM. Image and mind. Harvard University Press. 1980

13. Farah MJ, Hammond KM, Levine DN, Calvanio R. Visual and spatial mental imagery: Dissociable systems of representation. Cognitive psychology. 1988; 20(4): 439-462. doi: 10.1016/0010-0285(88)90012-6

14. Kosslyn SM, Thompson WL, Alpert NM. Neural systems shared by visual imagery and visual perception: A positron emission tomography study. Neuroimage. 1997; 6(4): 320-334. doi: 10.1006/nimg.1997.0295

15. Pylyshyn ZW. Imagery and artificial intelligence. Minnesota studies in the philosophy of science. 1978; 9: 19-55.

16. Marks DF. Visual imagery differences in the recall of pictures. British journal of Psychology, 1973; 64(1): 17-24. doi: 10.1111/j.2044-8295.1973. tb01322.x

17. McKelvie SJ. The VVIQ as a psychometric test of individual differences in visual imagery vividness: A critical quantitative review and plea for direction. Journal of Mental Imagery. 1995.

18. Holmes EA, Mathews A. Mental imagery in emotion and emotional disorders. Clinical psychology review. 2010; 30(3): 349-362. doi: 10.1016/j. cpr.2010.01.001

19. Chiesa M. Radical Behaviourism: The Philosophy and the Science. Authors Cooperative. Inc. pp. 1-241. 1994.

20. Shepard S, Metzler D. Mental rotation: effects of dimensionality of objects and type of task. Journal of Experimental Psychology: Human Perception and Performance. 1988; 14(1): 3-11.

21. Kosslyn SM. Information representation in visual images. Cognitive psychology. 1975; 7(3): 341-370. doi: 10.1016/0010-0285(75)90015-8
22. Intons-Peterson MJ. Imagery paradigms: How vulnerable are they to experimenters' expectations? Journal of Experimental Psychology: Human Perception and Performance. 1983; 9(3): 394-412.

23. Schmeidler GR. Visual imagery correlated to a measure of creativity. Journal of Consulting Psychology. 1965; 29(1): 78. doi: 10.1037/h0021660

24. Shaw GA, Belmore SM. The relationship between imagery and creativity. Imagination, Cognition and Personalit. 1982;2(2): 115-123. doi: 10.2190/4RGAY1A6-HEK5-LMF8

25. Holmes EA, Mathews A, Dalgleish T, Mackintosh B. Positive interpretation training: Effects of mental imagery versus verbal training on positive mood. Behavior therapy. 2006; 37(3): 237-247. doi: 10.1016/j.beth.2006.02.002

26. Nori R, Giusberti F. Predicting Cognitive Styles from Spatial Abilities. The American Journal of Psychology. 2006; 119(1):67-86. doi:10.2307/20445319

27. Palermo L, Piccardi L, Nori R, Giusbetti F, Guariglia C. The impact of ageing and gender on visual mental imagery processes: A study of performance on tasks from the Complete Visual Mental Imagery Battery (CVMIB). Journal of Clinical and Experimental Neuropsychology. 2016; 38(7): 752763. doi: 10.1080/13803395.2016.1161735

28. Palermo L, Piccardi L, Nori R, Giusbetti F, Guariglia C. Does hemi neglect affect visual mental imagery? Imagery deficits in representational and perceptual neglect. Cognitive Neuropsychology. 2010; 27(2): 115-133. doi: 10.1080/02643294.2010.503478

29. Jeannerod M. Mentalimageryinthemotorcontext. Neuropsychologia. 1995; 33(11): 1419-1432.

30. Laeng B, Teodorescu D. Eye scanpaths during visual imagery reenact those of perception of the same visual scene. Cognitive Science. 2002; 26: 207-231. doi: 10.1016/S0364-0213(01)00065-9

31. Paivio A. Mental comparisons involving abstract attributes. Memory \& Cognition. 1978; 6(3): 199-208. 